This is a self-archived version of an original article. This version may differ from the original in pagination and typographic details.

Author(s): Kangas, Emilia; Lämsä, Anna-Maija

Title: Leadership practices in relation to men's work-family balance in Finnish organizations

Year: 2021

Version: Accepted version (Final draft)

Copyright: (C) 2020 Informa UK Limited, trading as Taylor \& Francis Group

Rights: In Copyright

Rights url: http://rightsstatements.org/page//nC/1.0/?language=en

Please cite the original version:

Kangas, E., \& Lämsä, A.-M. (2021). Leadership practices in relation to men's work-family balance in Finnish organizations. Community, Work and Family, 24(5), 567-585.

https://doi.org/10.1080/13668803.2020.1728231 
Leadership practices in relation to men's work-family balance in Finnish organizations

Emilia Kangas* and Anna-Maija Lämsä

School of Business and Economics, University of Jyväskylä, Jyväskylä, Finland

*Emilia.e.kangas@jyu.fi

Mattilanniemi 2, FI-40014 University of Jyväskylä, FINLAND 


\section{Leadership practices in relation to men's work-family balance in Finnish organizations}

Leadership practices in organizations play an important role in shaping the conditions for employees' work-family balance. Previous research on the topic has mainly focused on women; fathers are said to receive little support from leadership for combining work and family. In this study, the focus is on men working in six Finnish organizations representing male-dominated, femaledominated and gender-balanced organizations. Although Finland is considered a frontrunner in gender equality globally, Finnish women still carry the main responsibility for housework and child-care. Through a discursive approach, we seek to answer the following research question: What kind of discourses do working men construct of leadership practices that affect their work-family balance? This study offers insights into the variety of understandings of how men's work-family balance is constrained and/or supported through leadership practices. Our conclusion is that the gender composition and degree of hierarchy of an organization affect leadership practices regarding men's work-family balance. A good relationship between leader and employee supports balance. Fatherhood seems to be handled differently from motherhood in leadership practices. The information produced in this study is not only important with respect to the quality of life of men and their families, but also necessary to advance gender equality in organizational life and society in general.

Keywords: fatherhood, discourse analysis, leadership practices, men, organization, work-family balance

\section{Introduction}

Previous research has mainly focused on how women balance work and family (Özbilgin, Beauregard, Tatli, \& Bell, 2011; Lämsä \& Piilola, 2015). Even though interest in studying especially men's work-family relationship has increased (e.g. Holter, 2007; Allard, Haas, \& Hwang, 2011; Hearn \& Niemistö, 2012; Burnett, Gatrell, Cooper, \& Sparrow, 2013; Gatrell \& Cooper, 2016; Kangas, Lämsä \& Heikkinen, 2017; 
Kangas, Lämsä \& Jyrkinen, 2019), few empirical studies have been made of men's work-family balance in the organizational context (Halrynjo, 2009; Allard, Haas \& Hwang, 2011), which is the focus in this study. It is not certain that women and men experience the work-family relationship in the same way (Eby, Casper, Lockwood, Bordeaux, \& Brinley, 2005). In addition, there has been a relative absence of studies considering men's work-family balance as a leadership issue. However, managers and leaders both set examples to organization members with their own parenting practices, and they are also in a position to influence their organisation's work-family practices. This means that managers themselves are the best role models for employees in feeling comfortable (or uncomfortable) taking advantage of work-family benefits (Ladge, Humberd, Baskerville Watkins, \& Harrington, 2015).

Leadership research has traditionally been leader-centred, i.e. focused on the individual leader, typically, the leader's traits and behaviour. The approach here emphasizes leadership as practice, which seeks to understand leadership activity wherever and however it arises (Raelin, 2016). Compared to more traditional approaches, this approach offers insights into the variety of understandings of how a work-family balance is constrained and/or supported through leadership practices. In line with Carroll et al. (2008), we think that the leadership-as-practice approach adopted here may enable men to put into words their experience of their work and family lives so that researchers and practitioners can engage with the everyday actions of leadership to support men's work-family balance. The kind of information we can access in this way is not only important for the quality of life of the men and their families but also necessary to advance gender equality in organizational life and society in general.

The opportunities and challenges men encounter in organizational life when trying to combine work and family can be considered a gendered context for the 
construction of leadership practices. In the traditional view of masculinity, men are typically viewed as beneficial financial actors; their fatherhood tends to remain invisible in organizational life (Tracy \& Rivera, 2010). The ideal employee in organizations is still a man without worries and obligations outside of work (Acker, 2011). This ideal employee is compatible with traditional masculinity and breadwinner fatherhood, which reinforces the idea that nurturing is mainly the responsibility of the mother, not the father (Marsiglio \& Roy, 2012). Burnett et al. (2013) argued that organizations and their leadership tend to close their eyes and ears when the question of parenthood concerns fathers. In other words, it seems that in the organizational context the responsibilities of fatherhood are not getting the same attention as the responsibilities of motherhood.

In this study, using a discursive approach, we seek to answer the following research question: What kind of discourses do working men construct of the leadership practices concerning their work-family balance? Our idea is that leadership practices in organizations play an important role in shaping the conditions affecting men's workfamily balance (Den Dulk, Peper, Kanjuo Mrčela, \& Ignjatović, 2016), and that different kinds of gender-specific organizational contexts may vary in this respect. To make this visible, organizations that represent male-dominated, female-dominated and gender-balanced organizations have been chosen for this study. Our idea is to uncover the day-to-day gendered habits and conventions of leadership practices that are often taken for granted in the organization (Carroll, Levy, \& Richmond, 2008), but which can significantly affect men's opportunities to balance their work and family lives (Kossek, 2016).

This research has been conducted in Finland, which is considered a front-runner in gender equality globally (The Global Gender Gap Report, 2020). In Finland, fathers are entitled to take paternity leave for a maximum of 54 working days (maternity leave 
is 105 working days), and either the mother or the father can take parental leave, which is 158 weekdays long. Finland has a long history of trying to encourage fathers to take greater responsibility for childcare, but women still bear primary responsibility for housework and child-care (Kela, 2017). Parental leave is used in Finland almost exclusively by mothers; one fifth of fathers do not use any at all of the available family leave (Kela, 2017). In a Nordic comparison, Finnish men are found to be at the bottom of the list for using parental leave (Cederström, 2019). According to Eerola et al. (2019), the most common barriers to fathers' taking parental leave in Finland are related to the family's economic situation and the father's job. About one third of the fathers whom they studied reported that the reason for not taking parental leave was being too busy at work (Eerola et al., 2019). According to Närvi (2018), one reason for fathers' unwillingness to use longer parental leave is the poor organizational practices of the workplace. Usually, companies do not take substitutes for the time fathers spend on parental leave. Such a practice hardly encourages men to take very long parental leave.

\section{Theoretical background}

We draw on the view that leadership is a process of social construction (Uhl-Bien, 2006). According to this viewpoint, leadership is done in various social practices in the organization (Denis, Langley \& Rouleu, 2010). In general, leadership practice refers to a cooperative action among participants who choose through their own conventions to reach a specific outcome (Raelin, 2010). From this point of view we can say that leadership in relation to work-family balance happens through various practices that emerge, unfold and become reality to organization members through their day-to-day experiences (Denis et al., 2010; Raelin, 2016).

According to Raelin (2003), conventional leadership can be replaced with the four C's of "leaderful practice": concurrent, collective, collaborative and compassionate 
practices. Concurrency in leadership means that any community can have more than one leader at the same time; there is no need for only one person to act and operate as leader. When the leadership is collective, on the other hand, it is not dependent on any one member or any one person's position, but rather everyone participates in practicing leadership. Collaborative leadership refers to the idea that all members of the community can be in control of and may speak for the entire community. In other words, collaborative leadership understands that everyone matters, and every opinion and contribution is important. Finally, compassion refers to the extent to which the parties are committed to taking into consideration and respecting the dignity of all members of the organization, regardless of status, background, gender or other diversity viewpoints. Overall, Raelin's idea of leaderful practice stresses the importance of the democratic aspect of leadership. The core of modern leadership is collaboration and mutuality (Raelin, 2003).

An alternative framework is suggested by Crevani et al. (2010), who claim that leadership practices can be viewed through the conceptualizations of direction, coorientation and action space. Direction in this case refers to the interaction between participants that sets the objectives for the activity, and it is related to the organization's strategies. For present purposes, this could be illustrated with the organization's workfamily strategy, and the overall direction that is set for the application of this strategy throughout the organization. The notion of co-orientation refers to diverging arguments and ideas among the parties in leadership relations, and the parties' opportunity to express disagreement: how far different views on the work-family relationship and related practices can be expressed and are taken into consideration and negotiated. Action space defines the limits to people's decision-making and action in the relationship, and their possibilities of bringing about change, for example in issues such 
as work-family balance. The action space can be seen to be related to power relations between the parties as well as to the power structure and hierarchy in the organization. In this framework, an organization's work-family practices should be seen against the background of the organization's overall direction and strategies, how far the organization tolerates disagreement and discussion, and how open it is to individual initiative and change.

According to Greenhaus and Powell (2017), work-family balance is an overall feeling that results from being effective and satisfied in two highly valued roles. Perceiving a balance between work and family leads to the feeling that one is effective and fulfilled in these two different parts of life, both of which are experienced as important, and this gives a person a sense of completeness, wholeness, and harmony. The balance between the two spheres can be supported by reducing work-family conflict, and by increasing work-family enrichment (Greenhaus \& Powell, 2017).

Although much of the research on the relationship between work and family has focused on the perspective of women, some studies have looked at the topic from men's point of view. For example, a study by Mills and Grotto (2017) among senior executives found that these men increasingly experience work-to-home conflict, despite bearing fewer care responsibilities at home than their spouses. It has also been shown that fathers who try to reduce their working hours to be more involved in family life often encounter a poor response in the organization and from the leadership (Gatrell, 2007; Holter, 2007; Lewis et al., 2009). This implies that organizations tend not to see men as caregivers at home. Allard et al. (2011) found that men felt that they receive little support from upper management in combining work and family, and that men's parenting responsibilities are not taken into account in organizational life. A study carried out by Kangas et al. (2017) concluded that despite some increase in male 
managers' orientation to family life, men still continue to construct their fatherhood mainly by drawing on traditional masculine ideology and holding on to their breadwinning role. At the same time, there are studies that challenge the idea of the traditional masculinity around working-class men (see Simpson \& Richardson, 2019). In recent decades, and especially in the Nordic context, the model of the male breadwinner has not been so dominant (Bonke \& Esping-Andersen, 2011). However, Whitehead (2014) claims that leadership and organizational cultures remain located in an arena that particularly privileges men's ways of working that are harmfully masculine and do not pay attention to other life spheres such as the family.

According to Acker (1990), organizational practices, for example leadership practices, are one field where a gendered substructure is negotiated and often contested in everyday life and where gendering processes may become visible. Studying leadership practices regarding the work-family balance of working men uncovers the gendering process of parenthood in the organizational world, especially because leadership is often intertwined with the traditional masculine gender stereotype. Despite the growing research interest in gender and leadership, and in general in equal opportunities, it seems that masculine logic is still alive in management and leadership (see Hearn, 2014; Powell, 2014). Therefore it seems that the existing traditional masculine leadership discourse and the caring fatherhood discourse are a long way apart, and men's work-family balance may not appear an important question in leadership at all. However, modern ideals of leadership include non-masculine tags like post-heroic, shared, and distributed leadership (Fletcher 2004) that are also described as feminine characteristics of leadership (Billing \& Alvesson, 2014; Lämsä \& Piilola, 2015). On the other hand, the idea of feminine leadership can be criticized for also 
tending to maintain traditional gender stereotypes, such as seeing women as more caring and empowering leaders than men (Billing \& Alvesson, 2000).

Although the feminization of leadership might not be a solution to gender equality in the work-family relationship, we think that any discussion that questions and makes visible the traditional masculine ways of doing leadership is one way of bringing about change. Billing and Alvesson (2014) call for cultural changes in leadership and the de-masculinization of leadership ideals. Both masculine and non-masculine leadership practices with regard to work-family issues affect understandings and discourses of men's work-family relationship and of fatherhood in general.

\section{Methodology}

Six organizations were studied. All the organizations are in the service sector, but the line of service varies. The service sector was chosen because it is the most important employer in the Finnish labor market (Statistics Finland 2016). Prior research shows that gender distribution in the organization can affect the leadership as well as employees' work and family relationship (Lämsä \& Piilola, 2015). In two of the organizations studied here (logistics and security) men dominate in terms of number of employees; two others are women-dominated (health care and the social sector); and in the last two organizations (a legal consultancy and IT) the proportion of men and women employees is more or less equal.

Discourse analysis (DA) was adopted in this study (Wetherell, 1998; Edley, 2001; Budds, Locke \& Burr, 2014). By discourse we refer to a rather coherent system of meanings which bring an object into being (Phillips \& Hardy, 2002). According to DA, discourse is both constitutive and constructive: it both shapes, enables and constrains possibilities, ideas, assumptions and understandings of specific topics, such as for example leadership practices in men's work-family balance (cf. Phillips \& Hardy, 2002; 
Budds et al., 2014). One advantage of DA is that it makes it possible to reveal ideas and assumptions that are taken for granted in a specific context and might be difficult to reveal by other methods (Phillips \& Hardy, 2002). Additionally, DA makes it possible to show the complexity of the phenomenon under study, and how this complexity is made sense of in Finnish organizational life (Fairclough, 1995).

Our research data was produced by means of open-ended interviews, which were conducted face-to-face and digitally recorded. The interviews were carried out during 2016. In the interviews, the aim was to avoid yes/no and short replies and to encourage discussion between respondent and interviewer (Roulston, 2012). The interviews included questions about the men's own experiences of their work-family balance and about the work-family practices of the organization. The research material includes 30 interviews with men, with three to six interviews from each organization. We applied to each target organization for permission to carry out the study with them and, permission having been granted, we found the interviewees with the help of the human resources management in each organization.

The respondents were selected following purposeful sampling (Patton, 2002). We selected men with children (mostly the children were the men's biological children, but in some cases the man was a stepfather). All of the men had or had had a spouse at the time when they were bringing up the children. From the family perspective, we targeted men with the most typical family structure, that is, in Finnish society, the dualearner model, i.e., with both parents working full-time (Eräranta \& Moisander, 2011). The men we interviewed ranged in age from 29 to 61 years old. From the organizational perspective, we looked for variation among the interviewees, so they represent various tasks and various hierarchical levels, from shop-floor to management. 
Because we promised the interviewees full anonymity, later in this article we use code OrgXManY, X standing for the organization, 1-6, and Y the number of the man interviewed in this organization (for example, Org1Man2 = organization one, the second interviewee from this organization).

In the analysis, we drew on Edley's (2001, p. 189) model of DA. First, the interviews were transcribed word for word. After reading the material through thoroughly, we made notes about the various ways the respondents described their work-family balance. Then we identified what kind of leadership practices were expressed in the texts about the men's work-family relationship. Next, we took a closer look at the subject positions that were made available to the participants mentioned in the texts (cf. Budds et al., 2014). A subject position refers to the identity constructions of actors and their relations to one another in discourse, or, as expressed by Edley (2001, p. 210), it is an identity 'location' that is made relevant to actors, such as leader and employee, within discourse. After this, we looked for dilemmas in the interpreted discourses, that is, those parts of the discourse where contrasting beliefs and values could occur (ibid, p. 203). Contrasting or opposing beliefs may develop, creating situations in which there can be more than one option as to what needs to be done and the participant must choose between them. Lastly, we focused on what kind of constraints and opportunities the discourses could create for men balancing between work and family (ibid; Willig, 2013; Budds et al., 2014).

\section{Results}

As a result, six discourses of working men's constructions of leadership practices concerning their work-family balance became defined. These discourses are summarized in Table 1. 


\section{TABLE 1 HERE}

Our discussion now turns to each of these discourses in turn.

\section{Male-dominated organizational context}

\section{Discourse of 'Mutual flexibility'}

In this discourse, a balance between work and family is very much appreciated, so the discourse opens up the possibility of men improving their work-family balance. One key to achieving balance is said to be flexibility on the part of both employee and leader. The leader's task is constructed as taking responsibility for creating the conditions for flexibility. Key leadership practices that promote flexibility are said to be, for example, not only a supportive and relaxed attitude and the behaviour of the leader, but also professional and fair planning of the work rota. The interviewees emphasized that it was assumed in the organization that when an employee showed flexibility in his attitude and behaviour, the leader too would be flexible in her/his practices and would take into consideration the employee's needs in the intersection of work and family. The respondents reported that they could, if necessary, go and do some shopping and speak to their family members on their mobile phone during the working day. They also mentioned that if they needed, for example, to arrange days off for family reasons, it was easy: all that was required was some negotiation with the supervisor. One respondent said this about it:

It's like this now, to that extent that with your own supervisor there's always been talk that if you've got some errands to do, so just go, he doesn't intend to check up on you, you yourself make sure that you get your work done. (Org1Man1)

The interviewees said that sometimes their shifts were quite suddenly lengthened if 
someone could not come to work, or that every now and then they needed to do some extra work at home after the working day was over. The men mentioned that it was quite common to stay longer at work or to take work phone calls when they were at home and not officially working. However, this was mentioned as being a pleasant practice. Flexibility in the relationship was said to arise from trust and open discussion between leader and employee.

In this discourse, the leader is constructed as a trusting, easy-going partner who does not closely monitor employees but rather allows them to work independently as long as the work is done. In relation to the leader, the employee is positioned as a collaborator who does what he has to do at work in the way expected of him. Leadership practices in this discourse resemble those of shared leadership, and are in contrast to ideas of traditional masculine leadership. Work and family are considered to be intertwined and mutually reconcilable when leader and employee have a good, easy relationship.

In sum, this discourse stresses that employees have flexibility in their workfamily arrangements but, conversely, the leader expects them to be flexible towards the organization's needs. Trust, easiness, openness and mutuality are core values called for to achieve collaboration in the leader-employee relationship in this discourse. However, it is problematic that although men are constructed as being relatively free to balance their family life with their work, ultimately the possibility of flexibility is related to the quality of the relationship between leader and employee: if the quality of this relationship is poor, collaboration and the employee's chances of achieving work-family balance can suffer. This is particularly the case because the organizations are said not to have any strategy for handling work-family balance, and this leaves it at the mercy of 
the quality of the relationship between the individual leader and each member of his team.

\section{Discourse of 'Encouragement to take paternity leave'}

In this discourse, the focus is on encouragement to take paternity leave. The leader's encouragement is considered a crucial leadership practice. The discourse is positive about family leave and the organization's support for men to take it. Paternity leave is constructed very positively, and as a good opportunity for fathers to get to know their new-born child. One leader reported how he encouraged fathers to take paternity leave:

I've told everyone for goodness sake now colleagues, take it, take the time off, because you won't get too many opportunities to do that in your life. (Org2Man3)

In this discourse, leadership is constructed as supportive and encouraging towards taking paternity leave. Especially older male leaders are described as motivators and as having an important role in relation to younger men in this respect. For example, one manager commented:

I have been saying to these our younger men that you should take time to stay home when you are having baby. (Org2Man5)

The leader's identity, then, is constructed as that of a wise elderly man who advises a young male employee to think about his family life. This means that the power to show direction in this matter is positioned in the leader, who has a lot of work experience as well as higher status in the organization's hierarchy. In the discourse, the emphasis is on the leader's paternalistic care of his employees. The employee is positioned in relation to the leader as a somewhat insecure younger man who may not realize how good it will be for him to give his family sufficient attention. The respondents brought out that they should take paternity leave not only to show caring fatherhood but also because their 
working hours were very demanding and it was good to take a break - called paternal leave - when the possibility arose. However, the men talked about using only paternal leave, not the longer parental leave that is available to both the mother and the father. " $I$ took all the leave that is for fathers" (Org2Man1), one respondent said.

Although, in this discourse, the elderly male manager supports the employee's work-family balance and creates room for the employee to focus on his family, the discourse constructs the male employee as a participative modern father but at the same time sticks to traditional gender roles - positioning the mother as the primary parent who will of course take long parental leave. Consequently, the respondents do not construct the man as an equal parent but rather as the mother's helper. Although it is argued that the leadership in the organization is supportive, it does in fact uphold and maintain this view.

\section{Female-dominated organizational context}

\section{Discourse of 'Flexibility for some employees'}

This discourse underlines the importance of balance between work and family. According to the respondents, the balance may be supported in order to allow flexibility in work arrangements. Practices such as the leader showing support and direction are said to be crucial. However, what is significant in this discourse and different from the previous discourses is that flexible arrangements in the organization are described here as being decidedly selective: the leader allows some employees to be flexible, but not all of them.

According to the interviewees, both the opportunities open to them and the leader's willingness to show flexibility varied from unit to unit and from one hierarchical position to another in the organization. Some units and their leaders were 
said to be very flexible and to take into account family situations in relation to work arrangements, while others were said to be stuck in old, rigid habits which only favoured particular groups of employees. Especially staff in higher positions, such as doctors in the health care organization, were said to have a good chance of flexibility. The respondents said that leaders treated the doctors quite differently and gave them many more opportunities to achieve work-family balance compared to those available to nurses and other groups. The result was inequality between different employee groups, as the following quote from a doctor's interview makes clear:

We've got flexible working hours, it makes no difference at all when you come to work or when you leave, that is within certain limits. With the nurses it's calculated down to the minute, so if you arrive five minutes earlier, a few minutes are always lost, and it's somehow sick, but maybe it'll be corrected sometime. (Org3Man3)

In this discourse, leadership practices in principle recognize the possibility of supporting work-family balance by means of flexible work arrangements. But despite these good intentions, the discourse constructs workers' identities as contrasting - they are either the victims of unfair treatment or privileged 'winners of the game' depending on their status and the unit in which they work. The unfairness in the application of flexibility in work-family issues is constructed as being at least partially a consequence of the incompetence of those in positions of leadership, but it is also due to the hierarchical organizational structure and culture in the health care and social service sectors. Consequently, in this discourse, the leader's identity becomes constructed as not only an incompetent, but also an uncritical follower of the existing organizational culture and hierarchy.

There is a contradiction here. On the one hand, flexibility in the work-family relationship is constructed as being important if one hopes to advance in leadership 
because it leads to a good end, that is, the well-being of organization members, and is considered a sign of caring and moral leadership. But at the same time the leader is constructed as immoral because s/he chooses to follow the organization's established habits and does not try to challenge them. In sum, in this discourse, leadership practices have the good intention of supporting a balance between work and family. However, the prevailing leader-centred organizational culture and hierarchical structure cause problems and result in leaders being uncritical, so that employees feel that they are treated unfairly with regard to their possibilities of achieving work-family balance. In other words, targeted compassion is not achieved very well in this discourse.

\section{Discourse of 'Top managers do not care but supervisors do'}

This discourse underlines the importance of leadership practices in promoting workfamily balance. The interviewees said that, in practice, the role of supervisors was crucial in achieving this balance. In particular, they spoke of how supervisors set an example in this by establishing guidelines and giving employees direction. Consequently, showing others what to do and supportive behaviour through rolemodelling are understood to be key leadership practices in this discourse. For example, one respondent spoke about this in the following way:

\footnotetext{
Those supervisors that I've had in different units have certainly encouraged me and have shown me that it's, that it is part of life that one has a life outside the workplace too, and you can talk about that and they themselves talk about it. (Org4Man4)
}

In this discourse, supervisors are constructed as good role models who emphasize the significance of the family in the employee's life. The discourse emphasizes that when supervisors themselves have their own experiences of reconciling work and family, they know how difficult it is for other people to handle the work-family relationship and they 
understand the problems. At the same time, top managers are constructed as invisible and impassive in their leadership practices in relation to work-family issues. As one HR director says:

I think the top management is the weak link here, they are quite invisible for employees in general and for these questions (work-family) there is no input from there. (Org3Man2)

The discourse opens up opportunities for men to balance their work and family, albeit in a restricted way. Overall, supervisors are constructed as empathetic and caring role models who take into consideration employees' work-family issues. According to the interviewees, it is easy to raise the subject of family in the daily interaction between supervisor and employee, and this highlights the importance of collaboration and strengthens both parties' action space to promote this balance.

In this discourse, the employee is positioned as the satisfied object of his supervisor's caring and empathetic leadership practices - key characteristics of traditional feminine leadership. Similarly, in this discourse, top managers are constructed as indifferent people who pay no attention to work-family issues. This means that top managers are positioned as distant in relation to employees $-\mathrm{a}$ sign of the traditional masculine hierarchical order of the organization. The conflict here is that supervisors are described as being able to create an open, caring environment that supports employees' work-family balance while at the same time top managers are sending employees contradictory messages. As a result, supervisors are said to have been left to deal with this on their own. 


\section{Gender-balanced organizational context}

\section{Discourse of 'In the hands of the leader'}

In this discourse, achieving a balance between work and family is emphasized; it is constructed as an ideal situation and an important aim that the leadership should support. However, the interviewees described themselves as having a tendency to work long hours and as being ready to be available 24/7. For example, one interviewee spoke of his commitment to work during his paternal leave:

\footnotetext{
And in fact I had all the equipment and everything at home, and I could certainly do work at home, and among other things those times when for example the baby was asleep during the day or whenever, then I certainly did some work. Really it was like, I was at home, but I did do some work when I could, so even in those circumstances I couldn't really cut myself off entirely from working life. (Org5Man6)
}

The men we interviewed attributed greatest responsibility for advancing the balance between work and family to leadership practices. In other words, they said that responsibility for achieving the balance and showing the way were in the hands of the leader. One reason for considering work-family balance to be a key leadership principle was that it could make the organization more attractive to potential employees and therefore support recruitment. Another reason was that balance supported the commitment of current employees. The interviewees thus justified the need for the leader to take responsibility for work-family balance pragmatically.

In this discourse, in their relationship to the leader, the respondents constructed their identity as highly work-driven professionals who were incapable of achieving work-family balance on their own. As the quotation above exemplifies, the interviewees positioned themselves primarily as employees even during their paternity leave, following the traditional gender role expectation of men's work orientation. The 
respondents emphasized two leadership practices that were crucial in helping them to advance their work-family balance: direction and control, and encouragement. Directing and controlling employees' working hours, for example, using an electronic system, was said to be an important leadership practice that prevented the employee working too many hours. Thus, the leader was positioned as the controller, in charge of the employee, who otherwise would not be able to take care of his work-family balance.

According to the respondents, in contrast to directing and controlling, leadership practices also need to involve encouragement and advice to men to promote the balance. The leader is thereby positioned not only as a boss or controller who prevents men from working too much but also as a respected advisor who encourages men to achieve balance between work and family and makes it possible for them to do so. Particularly the leader's encouragement to use facilities or services that were sponsored and recommended by the organization, such as childcare services for a sick child and a house-cleaning service, were said to be crucial. Moreover, when paternity leave was discussed, the interviewees stressed the role of a leader who was able to give credible advice about how and when to take the leave. For example, here one leader reports what he advised his subordinate:

One is soon going to have baby, so I just said to him that he should take the father's month in summer time, not when the baby arrives. In my experience it's better this way, you benefit more. (Org6Man3)

By combining the traditional masculine and feminine ways of leadership, this discourse creates opportunities for men to pay attention not only to work but also to the family sphere in their lives with the help, care, supervision and control of the leader. However, achieving a balance creates a dilemma. On the one hand, it is mentioned that giving advice and ideas and encouraging employees to achieve better work-family balance is a 
crucial leadership practice, but at the same time the leader is required to control the employee in how he organizes his work-family balance. In sum, in this discourse, to promote the balance the leader should actively pursue two quite contrasting alternative, namely controlling and encouraging.

\section{Discourse of 'Good to be seen'}

In this discourse the interviewees emphasized that it was important to be present in the office and work long hours. According to them, this was considered a merit in the organization. Therefore working from home was not constructed as a recommended habit, although one could do it every now and then. The interviewees reported that in practice they had all that was required to work from home and to ease the work-family balance in this way, but they stressed that it was better to be as visible as possible in the workplace, to be seen to be a good employee and to have career potential. For example, one respondent said:

So that in a way it is expected that people will be here, present, although in fact one could do the work anywhere and anytime, but in a way as far as time is concerned, despite that, yes I feel rather strongly that there's in a sense this unwritten and unspoken rule that one's at work when the office is open. (Org5Man6)

Especially positions of leadership in one field or another were constructed as positions where presence at the office and long working hours were important. Leaders were expected to stay there a long time and 'not show an empty office'. According to the interviewees, in their practices leaders set an example and showed employees that what was expected of them was a strong work-orientation and the habit of not being the first to leave the office in the evening.

If we demand a lot from the younger people then we should ourselves be the rolemodels and not be people who leave work early or at least not switch off the 
computer, particularly now when you can see who is online and who isn't. (Org6Man5)

In this way the discourse creates a leader's identity as someone who acts as a role model with regard to attendance at the workplace and who devotes himself to work life as fully as possible. In his relationship with the leader, the employee's identity is constructed as a follower, someone who follows the leader's role-modelling, and this strengthens the organizational culture of presenteeism.

This discourse produces constraints on the men with regard to integrating their work and family in a balanced way. The dilemma is that the work-centred rolemodelling is accepted in the organization, but this has a downside, that is, a negative impact on the men working there. A strong work-orientation and undervaluation of the man's family life can cause problems in both family life (e.g. neglect of the children, an unequal relationship between the partners in family obligations, problems in the marriage) and work life (e.g. stress, burnout, inefficiency due to excessively long working hours). In sum, the discourse highlights the belief that it is good for an employee's career if he is visible in the workplace as much as possible. The leader's willingness to be the role model in this leads to a vicious circle which encourages men's work orientation, reduces their opportunities to invest in family life and can also lead to negative results for the organization.

\section{Discussion}

Tracy and Rivera (2010) and Burnett et al. (2013) have claimed that fatherhood is likely to be invisible in organizational life. However, to the research participants in this study, the topic was not unknown, invisible or difficult to talk about. One explanation for the different result is that in the Finnish environment studied here, work-family balance has been a very topical issue in recent years, especially in public discussions (e.g. the 
media, politics) (Kangas et al., 2019). This may have increased the respondents' awareness of the topic and their willingness to talk about it.

The results showed that leadership practices were constructed as supportive and encouraging towards the advancement of fathers' work-family balance, especially in the male-dominated organizational context studied here: giving guidance, creating the conditions for flexibility and supporting cooperation and trust between leader and employee were regarded as key leadership practices. In this context, leadership practices were described as following the ideas of shared leadership and a caring orientation typically considered signs of feminine leadership (Billing \& Alvesson, 2014; Lämsä \& Piilola, 2015), caring fatherhood (Johnsson \& Klinth, 2007) and caring masculinity (Johansson \& Andreasson, 2017). This is an interesting finding because we studied mostly blue-collar service workers. One explanation for the supportiveness in this context may be that the work duties of these men can easily be assigned to others.

Although the ideas of supportive leadership make the topic visible and open the door to the advancement of work-family balance, ultimately the leadership practices described in the male-dominated context were constructed as being based on traditional gender roles (Tracy \& Rivera, 2010). The leader giving positive encouragement and showing direction (Crevani et al., 2010) can be understood on the one hand as enabling but on the other hand also as limiting the men's action space in their attempts to combine work and family. This is because in the discourses of the participants in the male-dominated organizational context, fathers were encouraged to take only short paternity leave, self-evidently reflecting the idea that fatherhood is only secondary parenting: primary responsibility for childcare is constructed as lying with the mother, and fathers are positioned as the mothers' helpers (see Hearn \& Niemistö, 2012). 
In the male-dominated context our findings are in contrast to those of various other studies. Allard et al. (2011), for example, argued that male employees experienced receiving little support from leaders when they tried to combine work and family. One explanation for the different result may be that the organizational cultures in the organizations studied here are quite relaxed and employee-orientated, and this has a positive effect on leadership practices that advance work-family balance. Our findings also do not resonate very well with the studies of Gatrell (2007), Holter (2007) and Lewis et al. (2009). They claimed that fathers who try to reduce their working hours in order to be more involved in family life often meet a poor response from the organization's leadership. Our results show that especially in the male-dominated organizational context, the support of management for male employees' work-family balance can be more complex and multifaceted than has been assumed in previous studies.

In this study, men were getting support for work-family balance, although only within limits. It seems that in the male-dominated organizational context, men are increasingly getting support for more involving fatherhood as long as they remain in the role of secondary parent: gender roles in parenting do not seem to have really been challenged in this context. One practical implication of this is that the development of a better work-family balance for men in a male-dominated organizational context needs to include leadership practices that challenge more radically the traditional gender roles, to open up more action space than is currently available for male employees' fatherhood. Top leaders could make a start and show the way with their own example, by themselves taking long parental leave.

In the female-dominated organizational context, leadership practices that emphasize a caring orientation were described as prevailing, especially among 
supervisors. What was crucial in this context was that a person's place in the hierarchy played an important role in one's opportunities to have work-family balance. The hierarchical organization and leadership are quite understandable in the health and social sector that was studied here (especially from the point of view of patient safety) but existing practices do tend to have a downside (Dennis et al., 2010). One disadvantage seems to be that an atmosphere of inequality creeps into the organization. As a result, especially supervisors in this context tend to face a moral paradox: they were described as showing care to their employees by fostering work-family balance but at the same time as upholding the hierarchical structure, which resulted in feelings of unfairness and limited the possibilities of achieving work-family balance. We think that the role of top management should be more active here: their position gives them the power to affect this situation. It seems that in the female-dominated organizational context, work-family balance is not so much a question of gender inequality as a question of inequality between different professions and their hierarchical positioning and valuation. Practical ways of developing work-family balance in this kind of context would be more discussion, and initiatives to reduce the unnecessary hierarchy. Additionally, leadership training could be particularly useful (Kossek, 2016): it has been confirmed that management training that focuses on family-friendliness is a good way of reducing work-family conflict (Hammer et al., 2011).

Interestingly, the discourse which stressed the most traditional masculine way of acting was found in the gender-balanced organizational context. In the 'Good to be seen' discourse, it was emphasized that leadership practices prioritize work over family. This discourse is in line with Whitehead's (2014, p. 455) argument that leadership as well as the general organizational context remain located in a discursive arena that privileges ways of working that are harmfully masculinist. The harm here is for the 
family, because they encourage fathers to be at work as much as possible. However, the other discourse that we found here, 'In the hands of the leader', in this context stressed supportive leadership practices with regard to men's work-family balance. The two discourses are clearly contradictory: one strives for a good balance between work and family while the other does not. This may be an indication of what Greenhaus and Powell (2017, p. 11) suggest: that many organizations claim to support work-family balance but their actual expectations of people in positions of leadership send the opposite message. It is possible that male employees are already well aware that involving fatherhood is nowadays socially accepted, but organizations and their leadership are still unwilling to support the idea in practice. We agree with the claim that masculine logic is still alive in leadership (see Hearn, 2014; Powell, 2014), but at the same time we would argue that ideals of fatherhood are now taking more fluid forms. On a practical level we therefore propose that in a gender-balanced organizational context prevailing masculine leadership practices need to be abandoned, for example by ending the culture of presenteeism.

Although there seems to be increasing recognition nowadays in organizations and among organizational leaders of the need for men's work-family balance (e.g. Holter, 2007; Halrynjo, 2009; Allard et al., 2011; Hearn \& Niemistö, 2012; Burnett et al., 2013; Kangas et al., 2019), it must be remembered that fathers do not have the same position as mothers in the organizational world. As shown here, there is still a tendency for fathers to be positioned as secondary parents, after mothers. Consequently, the achievement of work-family balance is not likely to appear the same to men and to women (Gatrell \& Cooper, 2016), and the advancement of men's work-family balance may not get as much consideration as that of women. This may be useful for those men who are more inclined to work than to participate in parenting. However, those who 
would like to participate equally with their spouses in parenting run the risk of being treated unfairly by leaders in the workplace. This can lead to the situation that the father who wants involving fatherhood is left on his own.

Overall, this study shows that leadership practices in organizational life in relation to men's work-family balance are diverse and full of contradictions. Previous studies have argued, on the one hand, that traditional masculine leadership is still strong in organizational life (e.g. Katila \& Eriksson, 2013; Powell, 2014) but, on the other hand, that leadership is moving towards a more participatory, non-hierarchical, flexible and group-oriented style (e.g. Fletcher, 2004; Billing \& Alvesson, 2014, p. 214). This study confirms that both tendencies - the maintenance of traditional masculine leadership and a transformation towards new modes of masculinities - are likely to coexist in leadership practices in relation to working men's work-family balance.

\section{Limitations and further research}

The present research has its limitations. In the first place, in this research, we focused on leadership practices in relation to men's work-family balance in six organizations in Finland that differed in their gender composition. This made the analysis compact, but the study has a limited sample. This study presents the Finnish societal context, but the Finnish welfare system is very dissimilar to many others in Europe, let alone to those in countries outside Europe. For the future, we call for more research in different kinds of organizations and other societies. Secondly, in this study, we used only men's interviews as the data source. Future studies that uncovered particularly organizational and leadership cultures using various data sets (e.g. observation, and documentary data in addition to interviews) could offer valuable insights into the topic. Additionally, it is important to compare the different perceptions and constructions of the topic by different genders. For the future, a longitudinal research setting could usefully explore 
the effect of changes in leadership on the advancement of men's work-family balance.

\section{Conclusion}

We conclude that the gender composition of an organization affects its leadership practices with regard to men's work-family balance. Additionally, the degree of hierarchy in the organization can be a factor. In organizations with rather informal leadership practices, employees are likely to have more flexibility about arranging their work-family relationship, although a good relationship between leader and employee seems to be a necessary condition for success.

Both the de-masculinization of leadership practices and the existence of traditional masculine leadership practices were identified in the interpreted discourses. This implies that some change in leadership in relation to men's work-family balance is emerging. Finally, the findings illustrate that fatherhood is still handled differently from motherhood in leadership, and indeed in organizational life generally. To advance gender equality in organizations, this should be changed and steps should be taken to ensure that fathers' possibilities of balancing work and family are similar to those of mothers. Finally, we argue that promoting modern, participative fatherhood is one way of advancing gender equality in organizations and in society in general.

\section{Conflict of Interest statement}

No conflicts of interest to disclose.

\section{References}

Acker, J. (1990). Hierarchies, jobs, bodies: A theory of gendered organizations. Gender \& Society, 4(2), 139-158.

Acker, J. (2011). Theorizing gender, race, and class in organizations. In E. Jeanes, D. Knights \& P. Y. Martin (Eds.), Handbook of gender, work and organization, (pp. 65-80). United Kingdom: John Wiley \& Sons Ltd. 
Allard, K., Haas, L., \& Hwang, C.P. (2011). Family-supportive organizational culture and fathers' experiences of work-family conflict in Sweden. Gender, Work \& Organization, 18(2), 141-157.

Billing, Y., \& Alvesson, M. (2000). Questioning the notion of feminine leadership: A critical perspective on the gender labelling of leadership. Gender, Work \& Organization, 7(3), 144-157.

Billing, Y., \& Alvesson, M. (2014). Leadership a matter of gender? In S. Kumra, R. Simpson \& R. J. Burke (Eds.), The Oxford handbook of gender in organizations (pp. 200-222). New York, United States: Oxford University Press.

Bonke, J., \& Esping-Andersen, G. (2011). Family investments in children. European Sociological Review, 25(1), 1-14.

Budds, K., Locke, A., \& Burr, V. (2014). Combining forms of discourse analysis: A critical discursive psychological approach to the study of 'older' motherhood. SAGE Research Methods Cases. SAGE Publications, Ltd.

Burnett, S. B., Gatrell,C. J., Cooper, C.L., \& Sparrow, P. (2013). Fathers at work: A ghost in the organizational machine. Gender, Work and Organization, 20(6), 632-646.

Carroll, B., Levy, L., \& Richmond, D. (2008). Leadership as practice: Challenging the competency paradigm. Leadership, 4(4), 363-379.

Cederström, C. (2019). State of Nordic fathers. Nordic Council of Ministers 2019. Copenhagen.

Crevani, L., \& Endrissat, N. (2016). Mapping the leadership-as-practice terrain. Leadership-as-practice: theory and application, 2, 21-49.

Crevani, L., Lindgren, M., \& Packendorff, J. (2010). Leadership, not leaders: On the study of leadership as practices and interactions, Scandinavian Journal of Management, 26(1), 77-86.

Den Dulk, L., Peper, B., Kanjuo Mrčela, A., \& Ignjatović, M. (2016). Supervisory support in Slovenian and Dutch organizations: a contextualizing approach. Community, Work \& Family, 19(2), 193-212.

Denis, J-L., Langley, A., \& Rouleu, L. (2010). The practice of leadership in the messy world of organizations. Leadership, 6(1), 67-88.

Eby, L. T., Casper, W. J., Lockwood, A., Bordeaux, C., \& Brinley, A. (2005). Work and family research in IO/OB: Content analysis and review of the literature (19802002). Journal of Vocational Behavior, 66(1), 124-197. 
Edley, N. (2001). Analysing masculinity: Interpretative repertoires, ideological dilemmas and subject positions. In M. Wetherell, S. Taylor \& S. J. Yates (Eds.) Discourse as data: A guide for analysis, (pp. 189-228). London: Sage Publications.

Eerola, P., Lammi-Taskula, J., O’Brien, M., Hietamäki, J., \& Räikkönen, E. (2019). Fathers' leave take-up in Finland: Motivations and barriers in a complex Nordic leave scheme. Sage Open, 9(4), 1-14.

Fletcher, J. K. (2004). The paradox of postheroic leadership: An essay on gender, power, and transformational change. The Leadership Quarterly, 15(5), 647-661.

Gatrell, C., \& Cooper, C.L. (2016) A sense of entitlement? Fathers, mothers and organizational support for family and career. Community, Work \& Family, 19(2), 134-147.

The global gender gap report. (2020). Geneva: World Economic Forum.

Greenhaus, J. H., \& Powell, G. N. (2006). When work and family are allies: A theory of work-family enrichment. Academy of Management Review, 31(1), 72-92.

Greenhaus, J. H., \& Powell, G. N. (2017). Making work and family work: From hard choices to smart choices. New York: NY, Routledge.

Halrynjo, S. (2009). Men's work-life conflict: career, care and self-realization: patterns of privileges and dilemmas. Gender, Work \& Organization, 16(1), 98-125.

Hammer, L. B., Kossek, E. E., Kent Anger, W. K., Bodner, T. \& Zimmerman, L. (2011). Clarifying work-family intervention processes: The roles of workfamily conflict and family supportive supervisor behaviors. Journal of Applied Psychology, 96(1), 134-50.

Hearn, J. (2014). Contextualizing men, masculinities, leadership and management: Gender/intersectionalities, local/transnational, embodied/virtual, theory/practice. In S. Kumra, R. Simpson \& R. J. Burke (Eds.), The Oxford handbook of gender in organizations (pp. 417ᄀ437). New York, United States: Oxford University Press.

Hearn, J. \& Niemistö, C. (2012). Men, 'Father Managers' and home-work relations: complexities and contradictions in national policy, corporations and individual lives. In P. MacDonald \& E. Jeanes (Eds.), Men's Wage and Family Work. (pp. 95-113). London: Routledge.

Holter, O. G. (2007). Men's work and family reconciliation in Europe. Men and Masculinities, 9(4), 425-456. 
Johansson, T., \& Andreasson, J. (2017). Fatherhood in transition: Masculinity, identity and everyday life. Springer. Palgrave Macmillan: London.

Johansson, T., \& Klinth, R. (2008). Caring fathers. The ideology of gender equality and masculine positions. Men and Masculinities, 11(1), 42-62.

Kangas, E., Lämsä, A-M., \& Heikkinen, S. (2017). Father managers (un)doing traditional masculinity. In A. Pilinska (Ed.), Fatherhood in contemporary discourse - Focus on fathers (pp. 17-30). Newcastle upon Tyne, UK: Cambridge Scholars.

Kangas E, Lämsä A-M., \& Jyrkinen M. (2019). Is fatherhood allowed? Media discourses of fatherhood in organizational life. Gender, Work \& Organization, 26(10), 1433-1450.

Katila, S., \& Eriksson, P. (2013). He is a firm, strong-minded and empowering leader, but is she? Gendered positioning of female and male CEOs. Gender, Work \& Organization, 20(1), 71-84.

Kossek, E.E. (2016). Implementing organizational work-life interventions: toward a triple bottom line. Community, Work \& Family, 19(2), 242-256.

Ladge, J. J., Humberd, B. K., Baskerville Watkins, M., \& Harrington, B. (2015). Updating the organization MAN: An examination of involved fathering in the workplace. Academy of Management Perspectives, 29(1), 152-171.

Lämsä, A.-M., \& Piilola, A. (2015). Women's leadership in Finland: The meaning of motherhood as related to leadership for women managers. In F. W. Ngunjiri, \& S. R. Madsen (Eds.), Women and leadership around the world. (pp. 87-105). Charlotte, NC: IAP.

Marsiglio, W. \& Roy, K. (2012). Nurturing dads. Social initiatives for contemporary fatherhood. New York: Russell Sage Foundation.

Mills, M. J., \& Grotto, A. R. (2017). Who can have it all and how? An empirical examination of gender and work-life considerations among senior executives. Gender in Management: An International Journal, 32(2), 82-97.

Närvi, J. (2018). Isä hoitaa vai hoitaako? Helsinki: Terveyden ja hyvinvoinnin laitos. Phillips, N., \& Hardy, C. (2002). Understanding discourse analysis. Thousand Oaks, CA.

Powell, G. N. (2014). Sex, gender, and leadership. In S. Kumra, R. Simpson \& R. J. Burke (Eds.), The Oxford handbook of gender in organizations (pp. 249־-268). New York, United States: Oxford University Press. 
Raelin, J. A. (2003). Creating leaderful organizations: How to bring out leadership in everyone. Berrett-Koehler Publishers. San Francisco: California.

Raelin, J. A. (2016). Leadership-as-practice: Theory and application. New York: Routledge.

Simpson, P., \& Richards, M. (2019). Reflexivity denied? The emotional and healthseeking resources of men facing disadvantage. Sociology of health \& illness, 41(5), 900-916.

Roulston, K. (2012). The pedagogy of interviewing. In J. F. Gubrium, J. A. Holstein, A. B. Marvasti, \& K. D. McKinney (Eds.), The SAGE handbook of interview research: The complexity of the craft, (pp. 61-74). Sage Publications.

Tracy, S.J., \& Rivera, K.D. (2010). Endorsing equity and applauding stay-at-home moms: how male voices on work-life reveal aversive sexism and flickers of transformation. Management Communication Quarterly, 24(1), 3-43.

Uhl-Bien, M. (2006). Relational leadership theory: Exploring the social processes of leadership and organizing. The Leadership Quarterly, 17(6), 654-676.

Whitehead, S. M. (2014). Masculinities in management: Hidden, invisible, and persistent. In S. Kumra, R. Simpson \& R. J. Burke (Eds.), The Oxford Handbook of Gender in Organisations, (pp. 438-459).Oxford University Press, Oxford.

Willig, C. (2013). Introducing qualitative research in psychology. UK: McGraw-Hill Education.

Özbilgin, M.T., Beauregard, T.A., Tatli, A., \& Bell, M.P. (2011). Work-life, diversity and intersectionality: a critical review and research agenda. International Journal of Management Reviews, 13(2), 177-198. 